\title{
Effectiveness test of dental hypnosis monitoring device
}

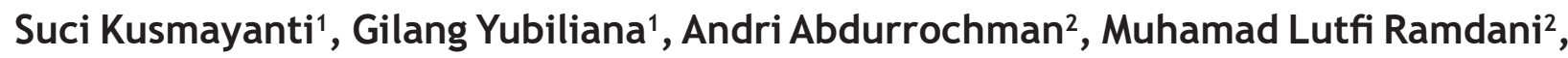 \\ Naufal Hilmi Fauzan²
}

\author{
1'Department of Dental Public Health, Faculty of Dentistry Universitas Padjadjaran, Indonesia \\ 2Department of Physics, Faculty of Mathematics and Natural Sciences Universitas Padjadjaran, \\ Indonesia
}

\begin{abstract}
Introduction: Modified Dental Anxiety Scale (MDAS) questionnaire is a simplified 5-point scale answering scheme, ranging from not anxious to extremely anxious. Anxious level can be reduced through dental hypnosis. Dental hypnosis monitoring device is an innovative device due to the Student Creativity Program Universitas Padjadjaran. The device can monitor a patient's consciousness by monitoring the brain wave level so that dentists can determine what steps to take when handling a patient. The effectiveness of this device has not been tested yet. This study was aimed to determine the effectiveness of the dental hypnosis monitoring device. Methods: A descriptive study was conducted on this study population, which was all the patients of Universitas Padjadjaran Dental Hospital (RSGM Unpad) who filled out the Modified Dental Anxiety Scale (MDAS) questionnaire. The sample criteria were people with moderate to high MDAS score and aged 17 years or above. Twenty-four people were obtained through consecutive sampling in one day. The study was held at Universitas Padjadjaran Dental Hospital by comparing the dental hypnosis monitoring device's performance with opinion from the dental hypnosis expert. Results: The overall success rate for the dental hypnosis monitoring device's effectiveness was $100 \%$ since the LED was always lit green during the hypnosis session, which was following the dental hypnosis expert assessment during processes. Conclusion: Effectiveness of the dental hypnosis monitoring device was proven to be $100 \%$ effective.
\end{abstract}

Keywords: dental hypnosis; dental hypnosis monitoring device; effectiveness.

p-ISSN: 1979-0201; e-ISSN: 2549-6212; Available from: http://jurnal.unpad.ac.id/pjd/article/view/22383

DOI: $10.24198 / \mathrm{pjd}$. vol33no1.22383

Submission: Feb 26, 2018; Accepted: Mar 31, 2021; Published online: Mar 31, 2021

\section{INTRODUCTION}

Dental hypnosis is an application of hypnosis to reduce pain and excessive anxiety in dental care without anesthetics or analgesic drugs. Dental hypnosis provides a relaxed state without drug administration, making patients calmer when the dentist takes action. ${ }^{1}$ An error can occur when the dentist evaluates the patient's hypnotic status because it is only a subjective evaluation. ${ }^{2}$ Until then, the novel instrument developed by Trivedi et al. $^{3}$ at Student Creativity Program in 2019

*Corresponding author: Suci Kusmayanti, Department of Dental Public Health, Faculty of Dentistry Universitas Padjadjaran, Indonesia. Street Sekeloa Selatan I, Bandung, West Java, Indonesia, 40132. Phone: +62 857-2105-5521; e-mail: sucikusmayanti@gmail.com 
which created a device that can monitor patient's consciousness condition called "Dental Hypnosis Monitoring Device. ${ }^{2}$

This device can monitor the patient's consciousness by monitoring the patient's brain waves so that the dentist can determine what steps should be taken when handling patients. This study's benefits for health practitioners, especially dentists who use hypnosis, are useful for providing information about one effective way of measuring the success of dental hypnosis. ${ }^{2} \mathrm{~A}$ dental hypnosis monitoring device is a device to monitor the patient's consciousness based on their brain wave frequency. ${ }^{2}$

This device defines the condition of patient consciousness to two conditions; hypnotic condition, when the brain wave frequency detected by the device is below $10 \mathrm{~Hz}$ and is not in hypnotic conditions if the device's brain wave frequency detected above $10 \mathrm{~Hz}$. Brain waves categorized into 4, Delta $(0.5-4 \mathrm{~Hz})$, Theta (4$8 \mathrm{~Hz})$, Alpha $(8-12 \mathrm{~Hz})$, and Beta $(12-22 \mathrm{~Hz}) \cdot 3,4,5$

Stated that brain waves were in the theta and alpha conditions when hypnotized. This device has an indicator of an LED light that will turn green when the patient is in hypnosis condition. ${ }^{2}$ The dental hypnosis monitoring device uses sensors that can directly record brain waves to the signal processing circuit using cables. In the signal processing circuit, the incoming signal will be processed on the microcontroller to determine the frequency of the patient's brain waves.

This tool uses a $5 \mathrm{~V}$ power source, from a power bank, cell phone charger adapter, or connected to a computer. When the device starts recording signals from brain waves, this tool will sort the brain waves obtained and show them on an indicator in the form of LED lights. According to previous research conducted by Naufal et al. ${ }^{2}$, this device has been tested at the lab level using the signal generator's help as input for the signal processing circuit, and the success rate of lab testing of the equipment was $80 \%$.

Dental hypnosis monitoring device was not tested on animals first, but directly tested on humans, because the device has been specially designed to monitor the process of dental hypnosis in humans, which was the research umbrella of GY during her doctoral study. The device is also one of the downstream parts of her research. ${ }^{6}$
Modified Dental Anxiety Scale (MDAS) questionnaire is a simplified 5-point scale answering scheme, ranging from not anxious to extremely anxious. Anxious level can be reduced through dental hypnosis. Dental hypnosis monitoring device is an innovative device due to the Student Creativity Program Universitas Padjadjaran. The device can monitor a patient's anxious by monitoring the brain wave level so that dentists can determine what steps to take when handling a patient.

However, this new device's effectiveness has not been tested, therefore, this study was aimed to determine the effectiveness of the dental hypnosis monitoring device. The definition of effectiveness is measured by how far the activity outcome compared to the purpose. ${ }^{7}$ The way to know effectiveness of this device was to compare the desired objectives with the research results. This study was aimed to determine the effectiveness of the dental hypnosis monitoring device.

\section{METHODS}

The method used in this study was descriptive, with a consecutive sampling technique. This study used the primary data obtained by setting the dental hypnosis monitoring device to patients with dental anxiety, which come to the Special Care Dentistry located at Universitas Padjadjaran Dental Hospital. The study population was all the people who filled the Modified Dental Anxiety Scale (MDAS) questionnaire. ${ }^{5}$ MDAS is a simplified 5 -point scale answering scheme, ranging from not anxious to extremely anxious. ${ }^{8}$

The modified dental anxiety scale (MDAS) contained 5 multiple-choice items including 1 If you went to your dentist for treatment tomorrow, how would you feel; 2 If you were sitting in the waiting room, how would you feel; 3 If you were about to have a tooth drilled, how would you feel; 4 If you were about to have your teeth scaled and polished, how would you feel and 5 If you were about to have a local anesthetic injection in your gum, how would you feel? The sample criteria were people with moderate to high MDAS score, and aged 17 years or above. Dental examination were carried out per complaints and the patient's condition after the hypnosis process. The number 


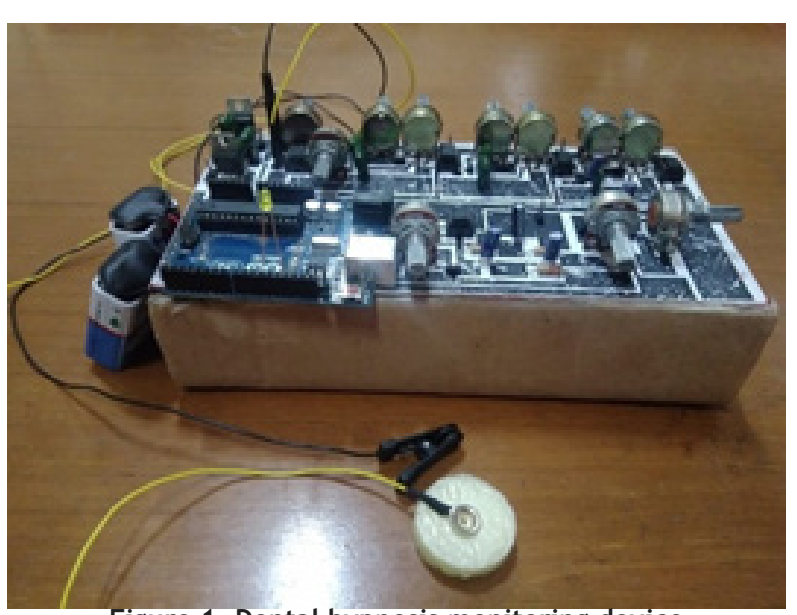

Figure 1. Dental hypnosis monitoring device

of samples in this study was 24 people consisting of 10 men and 14 women. The device needed in this study included ethical clearance, informed consent forms, MDAS questionnaire, sets of the dental hypnosis monitoring device, camera, and stationery. The research procedure performed as follows; first, distributing the MDAS questionnaire for samples that match the criteria. ${ }^{9}$

After that, the subjects instructed to sign informed consent. Then, a camera aimed at the LED indicator of the device. Next, two EEG electrodes will be set on the patient's head at Fp1 and A1, as shown in Figure 2. Both electrodes were sensors used by a dental hypnosis monitoring device to determine the patient's consciousness. After the condition settled, GY, as the dental hypnosis expert in this study, hypnotized the patient. After that, the data was collected, processed, and

\section{RESULTS}

Table 1. General characteristic based on sex and age

\begin{tabular}{ccc}
\hline Sex/Age & Quantity & Percentage \\
\hline Male/20 & 0 & $0 \%$ \\
Male/21 & 5 & $20.83 \%$ \\
Male/22 & 5 & $20.83 \%$ \\
Female/20 & 2 & $8.34 \%$ \\
Female/21 & 5 & $20.83 \%$ \\
Female/22 & 7 & $29.17 \%$ \\
\hline Total & 24 & $100.00 \%$ \\
\hline
\end{tabular}

This research was held at Universitas Padjadjaran Dental Hospital. The number of research subjects was 24 people with moderate to high dental anxiety based on their MDAS score. Each subject received the same treatment, placed by two EEG electrodes on their head and then

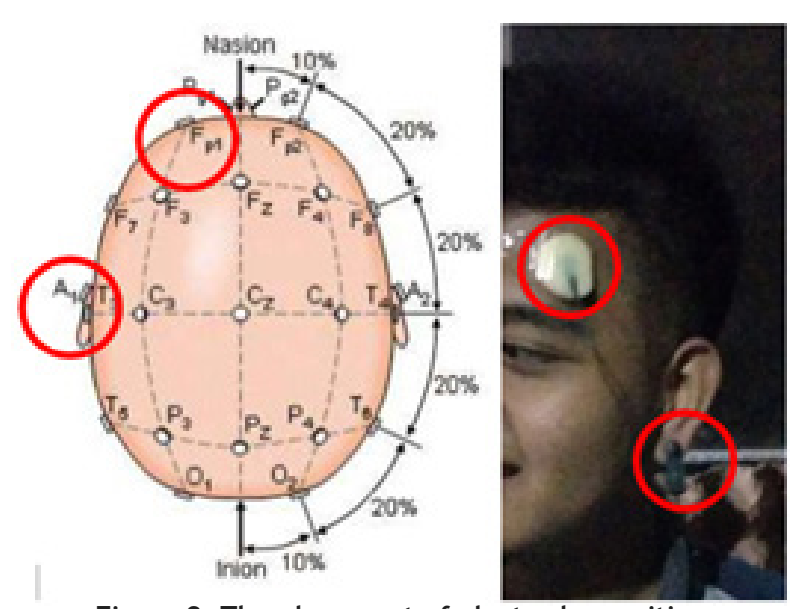

Figure 2. The placement of electrodes position

analyzed to determine the effectiveness of the dental hypnosis monitoring device by comparing the device's indicator with an opinion of the dental hypnosis expert. The Research Ethics Committee of Universitas Padjadjaran approved the study with clearance number 401/UN6.KEP/EC/2019, all participants gave their written informed consent to participate in this study.

The data obtained would be calculated the value of its effectiveness by comparing the number of successesful test with the total tests multiplied by $100 \%$, and the error percentage by substracting one hundred percent with the evectiveness percentage. ${ }^{10}$ The level of effectiveness was measured using the following indicators: very effective $(100 \%)$, effective $(90-100 \%)$, enough effective $(80-90 \%)$, less effective $(60-80 \%)$, and not effective $(<60 \%){ }^{11}$

Table 2. General characteristic based on age

\begin{tabular}{ccc}
\hline Age & Quantity & Percentage \\
\hline 20 & 2 & $8,33 \%$ \\
21 & 10 & $41,67 \%$ \\
22 & 12 & $50,00 \%$ \\
Total & 24 & $100,00 \%$ \\
\hline
\end{tabular}

hypnotized by a dental hypnosis expert. General characteristics of this research subject based on gender and age can be seen in Table 1.

Based on experiments performed on 24 samples, the dental hypnosis expert stated that the entire patients were hypnotized. Likewise, 
the dental hypnosis monitoring device lit the green LED indicator shortly after the dental hypnosis expert stated that the patient had been hypnotized. Study result proved that the device worked as expected.

This device had an LED indicator that will lit green when the brain wave frequencies were below $10 \mathrm{~Hz}$ or in hypnosis state, and remain red if the patient's brainwave frequencies were above $10 \mathrm{~Hz}$. Based on 24 times of device testing, all tests were successful. The calculation proved that the dental hypnosis monitoring device's effectiveness was $100 \%$ and is categorized as very effective, with the error percentage of $0 \%$.

Table 3. Final test result of dental hypnosis monitoring device

\begin{tabular}{|c|c|c|c|c|c|c|c|}
\hline \multirow{3}{*}{ No patient } & \multicolumn{4}{|c|}{ Test Result } & \multirow{2}{*}{\multicolumn{2}{|c|}{ Compa-tibility }} & \multirow{3}{*}{ Effectiveness } \\
\hline & \multicolumn{2}{|c|}{$\begin{array}{c}\text { Dental Hypnosis } \\
\text { Monitoring Device (LED) }\end{array}$} & \multicolumn{2}{|c|}{$\begin{array}{c}\text { Expert Dental Hypnosis } \\
\text { Assessment }\end{array}$} & & & \\
\hline & Green & Red & Hypnotized & Not Hypnotized & Yes & No & \\
\hline Number Patient & 24 & & 24 & & 24 & & $100 \%$ \\
\hline Error Percentage & 0 & & 0 & & 0 & & $0 \%$ \\
\hline
\end{tabular}

Based on experiments performed on 24 samples, Table 3 shows the dental hypnosis monitoring device's effectiveness and Table 4 shows the criteria of effectiveness level. The following are the formulas used to determine the effectiveness and error percentage of the device: Effectiveness $=$ (sigma) Succesful Tests, ratio (sigma) Tests $\times 100 \%$. Effectiveness $=24$ reduced $24 \times 100 \%$. Effectiveness 100\%. Error Percentage $=$ (sigma) Succesful Tests reduced Sigma Test, ratio (sigma) Tests, $\times 100 \%$.Error Percentage $=24$ ratio 24 reduced $24 \times 100 \%$. Error Percentage $=0 \%$. From the calculation, it can be concluded that the effectiveness of the dental hypnosis monitoring device is $100 \%$ and the error percentage is $0 \%$. The result shown in Table 3 proved that the device worked as expected.

This device has an LED indicator that will turn green when the brain wave frequencies are below $10 \mathrm{~Hz}$ or in hypnosis state. Remain red if the patient's brainwave frequencies are above $10 \mathrm{~Hz}$. Based on 24 times of device testing, all tests were successful. The calculation shows that the dental hypnosis monitoring device's effectiveness is $100 \%$ and is categorized as very effective, with the error percentage of $0 \%$.

Table 4. Criteria of effectiveness level ${ }^{8}$

\begin{tabular}{cc}
\hline Percentage & Criteria \\
\hline $100 \%$ & Very Effective \\
$90-99 \%$ & Effective \\
$81-89 \%$ & Enough Effective \\
$60-80 \%$ & Less Effective \\
$<60 \%$ & Not Effective \\
\hline
\end{tabular}

\section{DISCUSSION}

This research was held at Universitas Padjadjaran Dental Hospital. The number of research subjects was 24 people with moderate to high dental anxiety based on MDAS score. Table 1 shows the characteristics of samples obtained by gender and age. Based on Table 1, women had dental anxiety more than men, it also proved by the previous research by Patturaja ${ }^{12}$, said that anxiety seen in females is at a high level at $40 \%$, while anxiety seen in males is at a low level at $28 \%$. Age factor was also seen to be related to dental anxiety, Mohammed et al. ${ }^{13}$ stated in their study that younger age groups (15-25 years) were signifficantly has higher dental anxiety levels than the older age groups ( $>55$ years).

Subjects who experience dental anxiety were fitted with a dental hypnosis monitoring device, with electrodes located at Fp1 and A1 points, then hypnotized by a dental hypnosis expert until a mild trance stage, where brain waves begin to enter alpha waves. The consideration of electrode placement at the Fp (Frontal Polar) point is based on the theory from Sherwood ${ }^{14}$, stated that this section is the center of high 
intellectual function. Barry et al. ${ }^{15}$ also stated that more recent studies suggest that theta power, especially in the frontal region, differentiates highly hypnotizable subjects. Furthermore, the frontal lobes also regulate conscious movements, speech, motivation, and initiative. Moi et al, ${ }^{16}$ also stated that the sound frequency greatly affected the frontal area.

Point $\mathrm{A} 1$ is the reference point of $\mathrm{Fp} 1$, where the device will read the voltage difference between the two points. By fitting electrodes in that position, it is expected that the device can detect a person's brain wave frequency more effectively. ${ }^{15}$ Apart from the device, expert dental hypnosis also plays an essential role in determining its effectiveness. Because in this study, the device's effectiveness is determined by the compatibility between the device's results with the opinion of dental hypnosis titled a board-certified hypnotist.

When a hypnosis practitioner has been granted the designation of "Board Certified" in Hypnosis, it means that person has passed the peer-reviewed Guild Board Certification Exam), abbreviated $\mathrm{BCH}$, and the individual has demonstrated an advanced level of skill. ${ }^{17}$ The process should be undertaken by a well-trained and licensed hypnotist to establish the needed state of all those necessary conditions required for the study. ${ }^{18}$

The definition of effectiveness is measured by how far the activity outcome compared to the purpose. ${ }^{7}$ The result shown that the dental hypnosis monitoring device worked $100 \%$ effectively. The results of 24 times trials proved that all tests were successful because the device's results were in accordance to the dental hypnosis expert's assessment during the hypnosis processes. This result is corresponding with previous studies, where the success rate of lab testing of the device was also $80 \%$. The increase in the success rate might becasue of the methods testing difference.

Based on the data from Naufal's experiment, can be concluded that the device wasn't stable when it was injected higher than $13 \mathrm{~Hz}$ frequency, while in this study the monitored frequency was below $10 \mathrm{~Hz}$. The frequencies of the brain waves are evaluated every second, so that if the frequencies are beyond or below $10 \mathrm{~Hz}$, the indicator will lit red or green LED, sequentially. ${ }^{2}$ This device is still new and has not been tested to humans before.
Therefore, this study has its weakness. The research's weakness is that the sample used only represents the current proportion of the subjects at the moment so that the result cannot be generalised. Further research needs to be performed, not only comparing the device with a dental hypnosis expert but also compared to EEGs that can undoubtedly read and record human brain waves accurately.

\section{CONCLUSION}

Effectiveness of the dental hypnosis monitoring device was proven to be $100 \%$ effective.

\section{ACKNOWLEDGEMENT}

The authors would like to express a gratitude to Universitas Padjadjaran for the grant for this study through the Hibah Internal Universitas Padjadjaran 2019 - 2021 program.

\section{REFERENCES}

1. Malamed SF. A Guide to Patient Management. $6^{\text {th }}$ ed. St. Louis Missouri: Westline Industrial Drive; 2018. p. 92.

2. Malik NQ, Fauzan NH, Putri A, Abdurrochman A. Dental Hypnosis Monitoring Device. JIIF 2019; 3(1): 1-4. DOI: 10.24198/jiif.v3i1.20620

3. Trivedi KR, Thakker RA. Brainwave enabled multifunctional, communication, controlling and speech signal generating system," 2016 International Conference on Electrical, Electronics, and Optimization Techniques (ICEEOT), Chennai, India, 2016, pp. 48894893, DOI: 10.1109/ICEEOT.2016.7755650

4. Griffiths M. Hypnosis for dental anxiety. Dent Update. 2014; 41(1): 78-80, 83. DOI: 10.12968/denu.2014.41.1.78.

5. Griffiths MJ. The role of hypnotherapy in evidence-based clinical practice. Oral Dis. 2017; 23(4): 420-423. DOI: 10.1111/odi.12532.

6. Unnpad [homepage on internet]. Efektivitas Pendekatan Dental Hypnosis dan Dental Sedasi Inhalasi Sadar Terhadap Kadar Hormon Kortisol Saliva Sebagai Indikator Ansietas Dental dan Kualitas Hidup Pasien Pascapencabutan Gigi, Bandung: Unpad; c2016-2019 [updated Unpad. ac.id, 13/09/2016]. Available from: https:// 
www.unpad.ac.id/2016/09/dental-hypnosiskomunika-hipnodontik-efektif-turunkankecemasan-pasien/

7. Phillips DC. Encyclopedia of Educational Theory and Philosophy. $2^{\text {nd }}$ ed. Los angeles, California: SAGE Reference; 2014. p. 185.

8. Amir A, Kamate S, Gupta P, Gupta A, Singh J, Singh S. Assessment of Dental Anxiety Using MDAS (Modified Dental Anxiety Scale) among Students in Bareilly City - A Cross Sectional Study. Int J Contemp Med Res. 2018; 5(3): 4-6.

9. Giri J, Pokharel PR, Gyawali R, Bhattarai B. Translation and Validation of Modified Dental Anxiety Scale: The Nepali Version. Int Sch Res Notices. 2017; 29: 5495643. DOI: 10.1155/2017/5495643.

10. Gast DL, Ledford JR. Single Case Research Methodology. $1^{\text {st }}$ ed. New York: Taylor \& Francis; 2018. 436 p.

11. Ruliana T. The Local Original Revenue Analysis of East Kalimantan Province, Indonesian. Sci Pap Ser Manag Econ Eng Agric Rural Dev. 2015; 15(2). DOI : 10.33019/society.v8i2.202

12. Patturaja K. Sex Difference in Response to Dental Anxiety and Pain. J Pharm Sci Res. 2016; 8(6): 464-466.
13. Mohammed RB, Lalithamma T, Varma DM, Sudhakar KN, Srinivas B, Krishnamraju PV, Shaik $A B$. Prevalence of dental anxiety and its relation to age and gender in coastal Andhra (Visakhapatnam) population, India. J Nat Sci Biol Med. 2014; 5(2): 409-14. DOI: 10.4103/0976-9668.136210.

14. Sherwood L. Introduction to Human Physiology. $8^{\text {th }}$ ed. Cole: Yolanda Cossto. 2013; p. 836

15. Fogel BS, Greenberg DB. Psychiatric Care of the Medical Patient. $3^{\text {rd }}$ ed. New York: Oxford University Press; 2015. 1701 p. DOI: $10.1093 /$ med/9780199731855.001.0001

16. Han-Moi S, Ok-Hue C, Seok-Woo J, Ji-Hyang C, Hyun C, Won-Hyung L. Inaudible HighFrequency Sound Affects Frontlobe Brain Activity. Contemp Eng Sci. 2014; 7(23): 118996. DOI: $10.3389 /$ fpsyg. 2017.00093

17. Alabama, Delaware, Georgia, Indiana, lowa, Kansas, Kentucky et al. The National Guild of Hypnotists ; State Law and Legal Issuee 2017 Edition. United states: Knoxville; 2017. p. 2, 6

18. Hassan WMA. Hypnosis and Clinical Hypnotherapy in the Treatment of Psychological and Psychosomatic Ailments. Med J Babylon. 2014; 11(2): 1-15. 